\title{
A view on the iconic turn \\ from a semiotic perspective
}

\author{
August Fenk, Klagenfurt
}

Jedes Zeichen scheint allein tot. Was gibt ihm Leben?-

Im Gebrauch lebt es. Hat es da den lebenden Atem in sich?-

Oder ist der Gebrauch sein Atem?

Every sign by itself seems dead. What gives it life? -

In use it is alive. Is life breathed into it there? -

Or is the use its life?

Wittgenstein (2006[1933]432.)

\section{What is turning and what is iconic in the iconic turn?}

Media are not only a means of communication. From a cognitive perspective, they may be viewed as components of an external, auxiliary memory system (Schönpflug 1997), and contemporary cognitive science "construes cognition as a complex system in which cognitive processes are "embodied, situated' in environments, and 'distributed' across people and artifacts" (Nersessian 2007: 2). In man-machine communication, man-man-communication via digital machinery and especially in the World Wide Web (Heintz 2006, Steels 2006) the "external" components of this system have taken on more and more of the characteristics of our individual, "internal", living and active memory with its richness of sensual and symbolic formats. The intellectual challenge in the drafts of the "masterminds" of hypertext (Eisenstein) and multimedia (Lintsbakh) was the detection of temporal/spatial, mathematical and linguistic correspondences between such different sensual and symbolic representations (Bulgakova 2007, Tsivian 2007).

The so called "iconic" or "pictorial turn" was pulled along by the digital turn, and it may in turn have stimulated and accelerated the digital turn. And the increasing supply of pictorial materials - in TV, computer games, and the World Wide Web-may well have changed our visual literacy and our routines in the use of different kinds of pictures: The so called Flynn ef- 
fect - the significant improvement in test intelligence observed during the last decades - is assumed to reflect such tendencies (Neisser 1998), because this gain mainly affects subtests designed to measure non-verbal reasoning.

But what is turning and what is iconic in the iconic turn? The term iconic turn would imply a shift, i.e. an increase of iconic representations at the expense of non-iconic representations. But the World Wide Web is not a new single medium. Its users can upload or select texts, pictures and music files e.g. in order to "associate tags with these materials" (Steels 2006: 287). It has brought an increase of all types of "representation" and of course also an increasing supply of productions uniting such representations, such as in ordinary movies. The supply of pictorial material, let alone icons in a narrow sense of the word, by no means grew at the expense of e.g. texts or music, and perhaps not even any faster than the supply of such other materials. Thus the "iconic turn" is not really a turn. But what is iconic in this so called "turn"?

Inspired by the idea that the computer might overcome the book or even writing in general, the focus of the media debate has shifted from the relation between speech and written text to the relation between language and picture (Koch \& Krämer 1997: 19). What are the differences between the linguistic and the pictorial format? And what are their common features, especially in those pictures most commonly called "icons"?

In the following section I shall reconstruct relevant semiotic arguments and boil them down to a point concerning our quest (in Section 3) for iconicity in the "iconic turn". These arguments of course regard the nature of iconicity but cannot be discussed separately from the even more general question of how to define the sign. To be "in use" (see the above motto by Wittgenstein), i.e. to be produced and/or interpreted - is this a characterization of sign in function, or, more fundamentally, a precondition for the concept of sign? Can we think of sign and reference disconnected from actual interpretation, or even from the existence of a cognitive subject in principle capable of such an interpretation? Or even disconnected from communication systems? And is it really consistent to extend the concept of sign beyond communication systems (cf. the note of the "natural sign" and the "symptom") and to restrict, at the same time, similarity relations to a particular sign called the "icon"? 


\section{Similarity in the index and in the icon}

\section{1 Problems with "natural signs" and "symptoms"}

The index has always played a very special role in semiotic classification. Nöth (1997: 208 f) compares a "dogmatically dyadic" tradition differentiating only between iconic and symbolic representations and extending from the Epicureans via Saussure "to the Radical Constructivists of today" with a triadic tradition "extending from the Stoics to Peirce" who defined the indexical sign, i.e. a third form of representation, "according to criteria such as causality and spatial or temporal contiguity". These indexical signs, says Nöth, "are the most ignored ones in the theory of computational representation." I suspect, however, that the concept of the index was from the very beginning rather polyvalent and too wide for substantial applications. In Peirce, long the most frequently quoted semiotician, the concept of the index is so wide that it is an idle question whether or on which levels indexicality plays a role in the man-machine dialogue and in "computational representation". From an almost all-inclusive concept of the index follows an almost ubiquitous occurrence of indexical properties - inside and outside of information-processing and symbol-manipulating systems, irrespective of whether such a system belongs to artificial intelligence, as is the case of the computer, or to natural intelligence, as is the case of our "computer in the head", and irrespective of whether it functions on the basis of electrical signals and in a binary code or electro-chemical signals in a mixed, digital/ analogue code. According to Nöth's comparison, the present article inclines, though being free of constructivistic and of Saussurean ideas, to the "dogmatically dyadic" tradition. Let us start with a rather undogmatic view of Peirce's semiotic approach.

This view will focus on the trichotomy "most studied" in Peirce, i.e. the division of the sign into icons, indices, and symbols, and particularly on the definition of the index and its distinction from the icon. I shall precede it with a selection of the most informative passages I could find in Peirce's numerous writings and identify these paragraphs as "P1", "P2", "P3", and "P4" in the subsequent analysis.

"An icon can only be a fragment of a completer sign.

The other form of degenerate sign is to be termed an index. It is defined as a sign which is fit to serve as such by virtue of being in a real reaction with its object. For example, a weather-cock is such a sign. It is fit to be taken as an index of the wind for the reason 
that it is physically connected with the wind. A weather-cock conveys information; but this it does because in facing the very quarter from which the wind blows, it resembles the wind in this respect, and thus has an icon connected with it. In this respect it is not a pure index. A pure index simply forces attention to the object with which it reacts and puts the interpreter into mediate reaction with that object, but conveys no information. As an example, take an exclamation "Oh!" The letters attached to a geometrical figure are another case. Absolutely unexceptionable examples of degenerate forms must not be expected. / ... It is remarkable that while neither a pure icon nor a pure index can assert anything, an index which forces something to be an icon, as a weather-cock does, or which forces us to regard it as an icon, as the legend under a portrait does, does make an assertion, and forms a proposition." (1976 [1904]: IV, 242)

"But a symbol, if sufficiently complete always involves an index, just as an index sufficiently complete involves an icon. There is an infallible criterion for distinguishing between an index and an icon. Namely, although an index, like any other sign, only functions as a sign when it is interpreted, yet though it never happened to be interpreted, it remains equally fitted to be the very sign that would be if interpreted. /.../ The only way in which an index can be a proposition is by involving an icon." (1976 [1904]: IV, 256)

"... every sign is determined by its object, either first, by partaking in the characters of the object, when I call the sign an Icon; secondly, by being really and in its individual existence connected with the individual object, when I call the sign an Index; thirdly, by more or less approximate certainty that it will be interpreted as denoting the object, in consequence of a habit [which term I use as including a natural disposition] when I call the sign a Symbol. /.../

Indices, on the other hand, furnish positive assurance of the reality and the nearness of their Objects. But with the assurance there goes no insight into the nature of those Objects. The same Perceptible may, however, function doubly as a Sign. That footprint that Robinson Crusoe found in the sand, and which has been stamped in the granite of fame, was an Index to him that some creature was on his island, and at the same time, as a Symbol, called up the idea of a man. Each Icon partakes of some more or less overt character of its object." (1906:495 f)

"(And since this is the trichotomy I have most studied, and consequently most frequently mention, I will here say that the division is into, $1^{\text {st }}$, Icons, which represent their Objects by virtue of resembling them, as a geometrical figure in a geometry-book, or as any Diagram, or Array of letters in algebra, where the resemblance is not sensual but intellectual; $2^{\text {nd }}$ into Indices, which represent their Objects by virtue of being in fact modified by them, as a clinical thermometer may represent fever, or a letter attached to 
a figure of a triangle may from its position represent an angle of the triangle; and $3^{\text {rd }}$ into Symbols, which represent their Objects by virtue merely of the certainty (or probability) that they will be so interpreted; as any noun represents the thing for which it stands.)" (1976 [1908] III/2: 887)

We may note the essence of the index in Peirce: The index "represents" an object, draws attention to it and furnishes assurance of the reality of this object, by nearness and position (caption under a portrait; letter attached to a figure), "by being really and in its individual existence connected" with its individual object and by virtue of being "in real reaction" and "in fact modified" by it. Thus the index not only includes conventional signs, or, in terms of Langer (1942), "artificial" indices such as the letter attached to a figure, but also "natural signs" and "physical symptoms". ${ }^{2}$ But even "natural" indices - such as the weathercock's actual direction or footprints in the sand-may "involve an icon".

Peirce's "infallible" criterion for distinguishing between an index and an icon (P2) would imply that the icon, unlike the index, does not remain "equally fitted to be the very sign" as if interpreted. ${ }^{3}$ But why not? Are we really obliged to accept the actual direction of the weathercock (P1) as an icon instead of an index? And only because in Peirce's terminology the index is not allowed to be similar to its object and to convey information about this object? Peirce's "infallible criterion" (in P2) is, as far as I can see, not as clear as the criterion in an 1885 article where Peirce states that in the index there is "a direct dual relation of the sign to its object independent of the mind using the sign .... Of this nature are all natural signs and physical symptoms (3.361)" (Sebeok 1986: 49). But this older criterion contradicts the only criterion offered by Peirce for a general distinction between signs and non-signs: Signs are signs or become signs only by virtue of an interpretational act. Keller (1995: 118) also copes with this problem of an all inclusive sign by allowing the symptom a very special position within the signs. But he puts it the other way round: The symptom alone is a sign only when and as long as it is the object of someone's actual interpretation, while e.g. a symbol in a book remains this very same symbol irrespective of whether or not it is interpreted by somebody. This is, I think, a likely attempt to prevent the concept of the sign from becoming empty. But both the approaches of Peirce and Keller have to manage with the co-existence of more or less autonomous signs on the one hand and objects switching between existences as sign and non-sign on the other.

Peirce characterizes the natural index as that sign which exists without any "utterer" and, as one would say today, beyond any code. ${ }^{4}$ And what is it that 
makes something an icon? "No pure Icons represent anything but Forms; no pure Forms are represented by anything but Icons." (Peirce 1906:513) The consequence when this criterion is applied to language: "The arrangement of the words in the sentence, for instance, must serve as Icons, in order that the sentence may be understood. The chief need for the Icons is in order to show the Forms of the synthesis of the elements of thought." (Peirce 1906: 513). On the other hand, the "arrangement of the words" in the spoken or written sentence is, without any doubt, a matter of "position" and of temporal or local "nearness" to neighbouring words so that one should expect it being a case of idexicality. Needless to say that every sign in the narrow sense of the word, i.e. a component of a denotational system, necessarily functions at the same time as an index for other reasons as well, e.g. because they point to an "utterer" or author with this or that capability, intention, etc. According to Peirce (2.306) "it would be difficult, if not impossible, to instance an absolutely pure index, or to find any sign absolutely devoid of the indexical quality" (Spinks 1991: 64).

Peirce's explanations regarding the footprints (in P3) can hardly be understood without having in mind the whole set of such premises: The notion of a hardly existent "pure index" that does not convey any information; the pure icon representing nothing but a pure form; the implicational hierarchy in the first sentence of P2; and Peirce's notion (in 2.306, quoted from Spinks 1991: 65) that indices "have no significant resemblance to their objects".

- Those footprints found in the sand by Robinson are, first of all, an index for him that some creature was on his island. But since a pure index does not resemble its object and does not convey any information, they don't tell Robinson what sort of creature this might be.

- But they are also a symbol calling up the idea of man. We remember: A symbol represents its object by virtue merely of the certainty or probability that it will be so interpreted (P3, P4). This probability might be estimated as being higher in the footprints of another person than in the tracks of other creatures, including the imprints of the toes of different beach birds all around in the sand. And the probability that this person was still on the island might be rated higher in a man than in a seagull, for instance.

- But all that would not be sufficient for a really complete sign, since a symbol, "if sufficiently complete, involves an index, just as an index sufficiently complete involves an icon." (P2) Thus the indices "force" the footprint "to be an icon" (P1) so that it partakes in some more or less overt character of its object (P2, P3). 
Our rather restrictive conceptualizations suggest a much more parsimonious characterization of those footprints: They are simply a case of indexical similarity, i.e. a similarity indicating a certain causer! It is, of course, a similarity relation that indicates whether the imprints in the sand come from a man, or a dog, or a bird. The hollows in the sand resemble the feet of the particular causer in the way a coin resembles a particular matrix, and they also resemble, less specifically, the footprints of other (adult, male) members of our species. By virtue of these similarities they indicate another (adult, male) person as a causer that may be assumed to be still on the island, if one takes into account additional indications, such as e.g. the fresh look of the track. They are, like the tracks of beach birds, by no means a symbol, because they are not components of a code or of a denotational system. And they are not icons, not even icons in the broader sense of the word. Only if there is an agreement that e.g. a certain gait would mean a certain warning, can the footprints take on a symbolic function and "attain semiotic status" in the sense of Sebeok (see Section 2.2). Cases of iconicity (at least in a broader sense, see Section 3.2) would be if somebody draws the outline of a foot in the sand using his fingers, or if he moulds the sand with his hands in a way that the hollows look like a footprint, or if a youngster walks around in a way so that his track forms a heart or a boat.

\section{2 Delimiting the concept of sign}

All the above quotations and comparisons support, though not in a really systematic way, the view that Peirce's trichotomy of the sign (icon, index, symbol) can - if at all (Eco 1979: 178) — only be understood as a distinction between "isolate dimensions" (Ransdell 1986: 56) ${ }^{5}$ or "different uses" (Pelc 1986: 14) of signs; or, following Peirce's dictum (in P3) on the same "perceptible" that may "function doubly" as a sign, as different "functions" of signs (Fenk 1997) ${ }^{6}$. Corresponding terms (e.g. "the indexical function of a sign") also avoid the misunderstanding of the symbol, index, and icon-in Peirce usually used as nouns - as distinct classes of sign. But even with such a conceptualization of the index or indexical function one risks, if these terms are subsumed under sign or sign-specific functions, making the concept of sign all-inclusive and hence empty.

As far as I can see, a more tractable concept of sign can be achieved if we exclude the index from "external representations" and from sign-specific functions (Fenk 1997) and view indexicality as a fundamental cognitive principle pervading but also transcending referential systems and the world 
of signs (Fenk \& Fenk-Oczlon 2007: 889): The inferential or "indexical" interpretation of events is the essential function of our cognitive apparatus. Inference is much older and more fundamental than reference, i.e. the essential function of language. And it is a presupposition for reference.

The exclusion of indexicality from the sign and from sign-specific functions also means an exclusion of "indexical similarity", without any compromise. Neither indexicality, nor similarity, nor indexical similarity is sufficient for external representation and for sign. This offers a clear position in the cases of indexical similarity discussed e.g. in Sebeok and eight decades before Sebeok in Martinak. To begin with Sebeok:

In countless instances, images appear naturally, but copies of this sort are ordinarily devoid of semiotic value: a man's shadow cast upon the ground, his shape reflected in the water, his foot imprinted in the sand. Such everyday spatial images are necessarily endowed with certain physical, viz., geometric properties, but they attain semiotic status only under special circumstances. (Sebeok 1979: 123)

In the subsequent sentences Sebeok considers the possibility of a semiotic status at least in the last example, because here the image is "permanent"; it does not disappear with (the luminous source or with) the model. Which is not really a valid argument: a word, for instance, is a symbol and a sign irrespective of whether it is spoken and thereby transitory, or written and thereby permanent or "frozen". Martinak (1993[1901]: 30) shows more resolution in this respect. He points out that both the mirror-image and the photo-i.e. the permanent or "frozen" mirror image in terms of Sebeok-are so near to reality that one can hardly ask (in German) what they "mean" (bedeuten) and what they are a "sign" (Zeichen) of.

We use the term "indexical similarity" to characterize cases of similarity for which we cannot claim any semiotic status: the similarity between two animals indicating their relationship; the similarity between a tree and its shadow on the ground or between a bird's toes and their imprints in the sand; between a face and its image in the water or in a mirror, or between this face and its (digital or classical) photo; between a leaping cougar and a video-record of the scene. In the first examples similarity comes about by "natural" processes, in the latter by technical devices constructed, produced and released by persons. But the similarity we observe is not produced by these subjects! In order to illustrate the little but decisive step from "indexical similarity" to "iconic similarity": If the man whose shadow we observe enacts a shadow play, positioning his arm, hand and fingers in a way that the shadow resembles the silhouette of a swan or of a snapping wolf, then this is 
a case of iconicity. At least in a broader sense of the term:

\section{3 Delimiting the concept of the icon}

If similarity is considered to be necessary for those external representations or signs which one may call "icons" or "iconic", then it has to be a specific sort of similarity, i.e. the similarity established by a subject's simulating (imitating, modelling, ...) activities (Fenk 1997). Figure 1 comprises what remains after the elimination of the index, including cases of "indexical similarity": two basic types of representation and two possibilities to define the icon or iconicity.

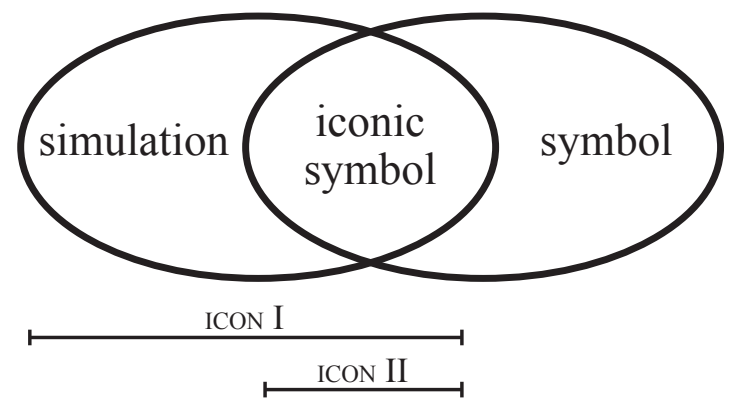

Fig. 1: A rather broad (I) and a rather restrictive (II) conceptualization of the icon (adapted from Fenk 1998: 305).

The essence of this conceptualization: Symbols are those signs that encode or denote, by virtue of their rule-based use (Keller 1995), concepts and propositions. Some of these symbols, such as pictograms and onomatopoetic words, show simulative properties. We may call them "iconic symbols", and this term is compatible with both Versions (I and II in Figure 1) of the definition of the icon and iconicity. The inverse expression-"symbolic icon" -, however, would be tautological in view of the more restrictive Version II, because according to Version II only symbols can be iconic. I am sympathetic to the more radical and, I think, more promising Version II. It is in line with those arguments foregrounding the symbol (allusively in Ransdell; our Footnote 5) and the existence of a code (Eco 1979: 121) but preserves, unlike in Eco, iconicity as a relevant function of specified signs.

But I have to admit that these arguments shift some questions of definition to the terms code and denotation. For instance: Despite the fact that in iconic signs the similarity between the representation and the represented is produced by somebody, one need not agree with Eco (1979: 200) that every mode of producing similarity necessarily follows a code and that the detection of produced similarity necessarily "requires a trained eye" and "must be 
learned". Our highly developed abilities to detect patterns and similarities are much older than human culture, and iconicity is a means of using these abilities e.g. in order to establish a new code or new elements of an already established code.

\section{Iconicity and indexicality in the New Media}

In Section 1 we questioned the appropriateness of the term "iconic turn", since the supply of picture material did not increase at the expense of the supply of e.g. texts and music files. One might reply that the digital technique used in the new media is in many cases per se a picturing technique-e.g. in the case of a digital camera or in the scanner that produces a picture of a text or a picture of a picture. But this argument would not hold in the light of our semiotic analysis in Section 2. When applying semiotic concepts to the media we have to distinguish between techniques, processes and products of creating something, and techniques, processes and products of storing, reproduction, duplication, transmission, distribution, and retrieval. The digital technique belongs, first of all, to the latter. When used in order to record something - this "something" may or may not be iconic - the result is "only" a case of indexical similarity. The similarity between the record and the object of the record does not come about by a subject's simulating activities. The digital camera may produce a picture of a person's face (i), or of the mirror-image or a photo of this face (ii), or of a freehand sketch of this face (iii). In the last of these instances the object is iconic, but in none of the instances is the digital record iconic. Example (i) illustrates the simple case of the production of indexical similarity, and in the instances (ii) the record produces indexical similarity with something that has indexical similarity with the face. In (iii) the record of the iconic representation is no more iconic than the mirror image of the sketch would be. If, however, somebody uses his image in the mirror in order to draw a self-portrait, he produces something that is iconic at least in the broader sense of the term.

"Indexical similarity" indicates a similarity between model and reproduction, but especially in digital "photography" this is something we never can be sure about. While the classical film document is almost unforgeable (Matuszewski 1898), the digital technique offers outstanding possibilities for forgeries: It is no problem to extend the nose of a politician in a way that makes him look like Pinocchio, or to apply bullet wounds to the forehead of a terrorist leader who in reality is living in the best of health. Such forgeries are in fact iconic, and due to the potentials of digital communication it 
is extremely difficult to identify "indexes" indicating a forgery and pointing to specific falsifiers and to those who launched the forgeries in the World Wide Web. Less scheming are the digital reworks of the pictures of prominent actors to make them look like prisoners (www.worth1000com, April 27, 2007)

In such forgeries and reworks the digital technique is not simply used for recording, storing and transmitting something, but for modifications where the authors actually simulate something and thus really produce iconic representations. But the digital technique offers the potential not only for modifications of given originals, but also for creating "completely new" and "genuine" artefacts from the very beginning.

On high artistic and technical levels this potential is used e.g. for the creation as well as the animation of figures in the "cyber arts" and in the hybrid arts, in "cartoon films" and computer games, or for the creation and animation of blueprints of e.g. airplanes in computer aided design. At a first glance one might deny the iconic character of forgeries, of fantastic images and of the drafts of an airplane with the argument that none of these creations simulates an object as (already) existing in our perceptual world. But, actually, our fantasy cannot invent and imagine "completely new" things. All our fantastic images go back to perceptually familiar materials and properties to form new combinations: as in the unicorn, which combines a horse with a narwhal horn, or in the soft watches in Salvador Dali's "The persistence of memory" that exhibit properties of a face cloth or the flow characteristics of heated plastic (watches). There is no medium that can go beyond this principle, irrespective of the tools available and of the ways they are used.

On a lower level, graphic tools can be used for simple, non-animated drawings and drafts such as the logo in Figure 2. I was quite optimistic that the company in question would acquire this idea for an improved logo, but its agency in Germany did not want it for some reason or other. So I can use it here not only as a further example of iconicity as established by digital techniques, but, moreover, as a rather untypical instance concerning an assertion in Wittgenstein (2006 [1933]): "We do not realize that we calculate, operate with words, and in the course of time translate them sometimes into one picture, sometimes into another." (449.) One may add that usually we also do not realize that such mental images or "mental models" (JohnsonLaird 1983) evoked by verbal expressions often become manifest in real pictures such as diagrams and pictograms. Pictograms are the prototypical icon that can be localized in the overlap of simulation and symbol in Figure 1. And many logos are pictograms. A pictogram such as the well known post horn logo is a really "complete" sign: As a symbol it represents the country's 
postal service. As an icon it represents a post horn. And it offers unlimited indexical properties: From the place of application we may infer that this car or building is used or was used by the postal service, or that the "Hotel Post" was in use a century ago, and that the colour of the logo must have been refreshed very recently, etc. Pictograms can be viewed as elements of written schemata (Fischer 1997) and are used and interpreted in similar ways as synecdochic or metonymic verbal expressions. Figural thinking is reflected in both the diagrams of the special type called "logical, non-representational, arbitrary pictures" and the corresponding figures of speech, i.e. spatial metaphors. These diagrams capture, as it were, different figures of speech that can be assigned to different metaphor families, such as the path, the inclusion, and the subsumption metaphors (Fenk 1994, 1999).
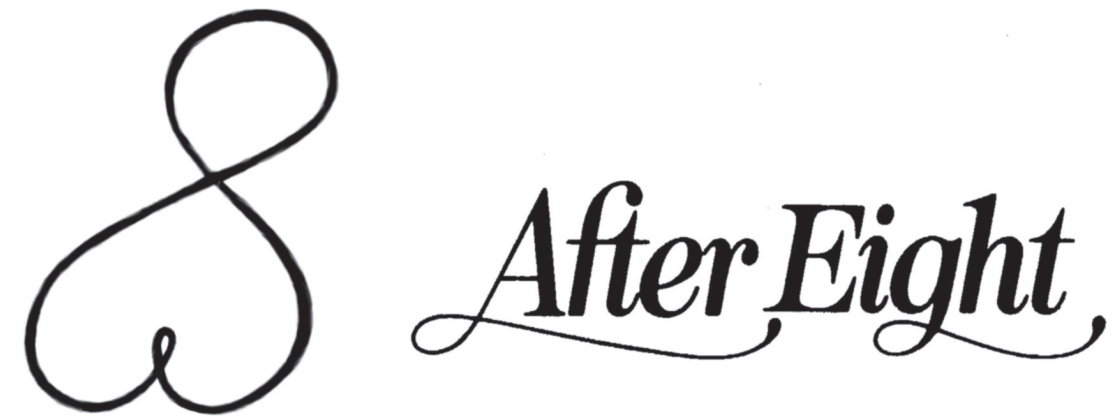

Fig. 2: A draft of a new logo for an old trademark

The results of digital recordings and transmissions resemble the model or reproduce it in analogue form. But this is a case of what we have called "indexical similarity", not of iconicity, if iconicity is reserved for cases of similarity established by a subject's simulating activities. The mirror, says Pirenne (1970: 11), "does not represent reality, it presents to us reality". This is exactly what digital records do as well. But the "reality" presented to us by the mirror, or by a photo or the digital record, may of course be an artefact such as a cubistic portrait — an icon in the broader sense of the word - or a specified isotype by Neurath, i.e. an icon in the restricted sense of the word. The portrait by Picasso and the isotype by Neurath are as real as the real models of these representations.

\section{Endnotes}

${ }^{1}$ The Radical Constructivist E. v. Glasersfeld (1982:194), however, considers the Peircean approach to be rather promising, at least as compared with the approach of Ogden \& Richards (1923). 
${ }^{2}$ This distinction between conventional and natural signs calls up a related distinction in German between Zeichen ( $\sim$ sign) and Anzeichen ( $\sim$ indication, indicator). This is not a distinction that is used consistently, and in many cases Anzeichen can be replaced by Zeichen: The dark clouds on the horizon are not only Anzeichen of a storm coming up; one may also say that they "mean" (bedeuten) or are a "sign" (Zeichen) of a storm coming up. But, conversely, Zeichen cannot in every case be replaced by Anzeichen, e.g. when there is direct talk about the utterer of a sign: "Zum Zeichen der Versöhnung gab er ihm die Hand." ("As gesture of good will he shook his hand.")

${ }^{3}$ In terms of Wittgenstein's metaphor (see our motto under the title of the paper), a sign not interpreted by anyone still exists but is not alive. This is one of several points where one is tempted to ask - in analogy to Rellstab's (2007) question "How much Grice is in Peirce?"- -how much Peirce there is in Wittgenstein.

${ }^{4}$ Taking up arguments by Grice (1957), Sperber \& Wilson (1986) investigate relations between communication and cognition and differentiate between a "code theory" and an "inferential theory" of communication. From their point of view, Peirce's semiotic approach, or also the Saussurean semiological approach, "is a generalisation of the code model /.../ to all forms of communication." (Sperber \& Wilson 1986: 6). But, actually, Peirce's generalization extends even far beyond communication.

${ }^{5}$ According to Ransdell (1986: 56f) Peirce's “conception of the symbol, along with the coordinate conceptions of the icon and the index /.../ can function in application 
only to isolate dimensions of the significance in things, but not to classify or sort out things into distinct groups /.../."

${ }^{6}$ Similarly, Eco (1979) succeeds, despite of his radical rejection of Peirce's "untenable trichotomy" (p 178) and especially of the notion of the "iconic signs", in isolating different "modes of producing sign-functions" (p 217).

\section{References}

Bulgakova, Oksana 2007 "From stage to brain: montage as a new principle of a scientific narrative", in: International Association for Semiotic Studies (ed.), $9^{\text {th }}$ World Congress of Semiotics. Communication: Understanding, Misunderstanding, Helsinki: Hakapaino, 89-90.

Eco, Umberto 1979 [1976] A Theory of Semiotics, Bloomington: Indiana University Press.

Fenk, August 1994 "Spatial metaphors and logical pictures", in: Wolfgang Schnotz and Raymond W. Kulhavy (eds.), Comprehension of Graphics (Advances in Psychology 108), Amsterdam: North-Holland, Elsevier Science B.V., 43-62.

Fenk, August 1997 "Representation and Iconicity", Semiotica 115, 3 / 4, $215-234$.

Fenk, August 1998 "Symbols and icons in diagrammatic representation", Pragmatics and Cognition 6 (Special Issue on The Concept of Reference in the Cognitive Sciences), 1/2, 301-334.

Fenk, August 1999 "Ikonische Symbole und visuelle Metaphern", Papiere zur Linguistik 61, 2, 119-138.

Fenk, August and Fenk-Oczlon, Gertraud 2007 "Inference and Reference in Language Evolution“, in: Stella Vosniadou, Daniel Kayser, and Athanassios Protopapas (eds.) EuroCogSci07, The European Cognitive Science Conference 2007, Hove: Lawrence Erlbaum Associates, 889.

Fischer, Martin 1997 "Schrift als Notation", in: Peter Koch and Sybille Krämer (eds.) Schrift, Medien, Kognition: über die Exteriorität des Geistes, Tübingen: Stauffenberg Verlag, 83-101.

Grice, H. Paul 1957 "Meaning”, The Philosophical Review 66, 377-388.

Heintz, Christophe 2006 "Web Search engines and distributed assessment systems. Collaborative tagging as distributed cognition", Pragmatics \& Cognition 14 (Special Issue on Cognition and Technology: Distributed Cognition), 2, 387-409.

Johnson-Laird, Philip N. 1983 Mental models: towards a cognitive science 
of language, inference, and consciousness, Cambridge: Harvard University Press.

Keller, Rudi 1995 Zeichentheorie, Tübingen: Francke.

Koch, Peter and Krämer, Sybille 1997 "Einleitung", in: Peter Koch and Sybille Krämer (eds.) Schrift, Medien, Kognition: über die Exteriorität des Geistes, Tübingen: Stauffenberg, 9-26.

Langer, Susanne 1942 Philosophy in a New Key, Cambridge (Mass.): Harvard University Press.

Martinak, Eduard 1993 [1901] Psychologische Untersuchungen zur Bedeutungslehre, Leipzig: J.A. Barth. [Reprinted in Kodikas/Code, Ars semeiotica 16 (1/2), 125-126.]

Matuszewski, Boleslas 1998 [1898] "Eine neue Quelle für die Geschichte. Die Einrichtung einer Aufbewahrungsstätte für die historische Kinematographie", montage/av-Zeitschrift für Theorie \& Geschichte audiovisueller Kommunikation 7, 2, 6-12.

Neisser, Ulric (ed.) 1998 The rising curve: Long-term gains in IQ and related measures, Washington, DC: American Psychological Association.

Nersessian, Nancy J. 2007 "Model-based Reasoning in Distributed Cognitive-Cultural Systems: Studies of interdisciplinary research labs", in: Stella Vosniadou, Daniel Kayser, and Athanassios Protopapas (eds.) EuroCogSci07, The European Cognitive Science Conference 2007, Hove: Lawrence Erlbaum Associates, 2.

Nöth, Winfried 1997 "Representation in Semiotics and in Computer Science", Semiotica 115, 3 / 4, 203-213.

Ogden, Charles K. \& Richards, Ivory A. 1923 The meaning of meaning, London: Routledge \& Kegan.

Pelc, Jerzy 1986 “Iconicity: Iconic Signs or Iconic Uses of Signs?”, in: Paul Boissac, Michael Herzfeld, and Roland Posner (eds.), Iconicity: Essays on the Nature of Culture; Festschrift for Thomas A. Sebeok, Tübingen: Stauffenberg-Verlag, 7-15.

Peirce, Charles S. 1906 "Prolegomena to an Apology for Pragmaticism", The Monist VI, 4, 492-546.

Peirce, Charles S. 1976 [1908] "[Letter to] P.E.B. Jourdain", in: Carolyn Eisele (ed.), The New Elements of Mathematics, 3/2, Berlin: Mouton; Atlantic Highlands, NJ: Humanities Press, 879-888.

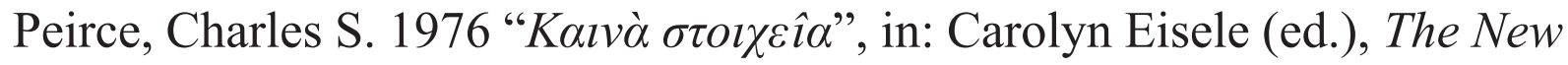
Elements of Mathematics, 4, Berlin: Mouton; Atlantic Highlands, NJ: Humanities Press, 236-263.

Pirenne, Maurice H. 1970 Optics, Painting and Photography, Cambridge: Cambridge University Press. 
Ransdell, Joseph 1986 “On Peirce's conception of the iconic sign”, in: Paul Boissac, Michael Herzfeld, and Roland Posner (eds.), Iconicity: Essays on the Nature of Culture; Festschrift for Thomas A. Sebeok, Tübingen: Stauffenberg-Verlag, 51-74.

Rellstab, Daniel H. 2007 "How much Grice is in Peirce?" in: International Association for Semiotic Studies (ed.), 9th World Congress of Semiotics. Communication: Understanding, Misunderstanding, Helsinki: Hakapaino, 369.

Schönpflug, Wolfgang 1997 "Eigenes und fremdes Gedächtnis. Zur Rolle von Medien in Erweiterten Gedächtnissystemen", in: Peter Koch and Sybille Krämer (eds.), Schrift, Medien, Kognition: über die Exteriorität des Geistes, Tübingen: Stauffenberg, 169-185.

Sebeok, Thomas A. 1979 The sign \& its masters, Austin \& London: University of Texas Press.

Sebeok, Thomas A. 1986 I think I am a verb. (More contributions to the doctrine of signs), New York \& London: Plenum Press.

Sperber, Dan and Wilson, Deirdre 1986 Relevance: communication and cognition. Oxford: Blackwell.

Spinks, C.W. 1991 Peirce and Triadomania: a walk in the semiotic wilderness, Berlin/New York: de Gruyter.

Steels, Luc 2006 "Collaborative tagging as distributed cognition". Pragmatics \& Cognition 14 (Special Issue on Cognition and Technology: Distributed Cognition), 2, 287-292.

von Glasersfeld, Ernst 1982 "Subitizing: the role of figural patterns in the development of numerical concepts", Archives de Psychologie 50, 191218.

Tsivian, Yuri 2007 "Synesthesia to Multimedia: How Lintsbach's Old Semiotic Fantasy Looks in the Digital Age", in: International Association for Semiotic Studies (ed.), 9th World Congress of Semiotics. Communication: Understanding, Misunderstanding, Helsinki: Hakapaino, 14-15.

Wittgenstein, Ludwig 2006 [1953][1933] Philosophical investigations, Malden (MA): Blackwell Publishing. 